\section{Radiologists and radiographers must remain the custodians of diagnostic radiation}

To the Editor: The editorial in the March 2010 issue of the SAJR by Professor Lotz ${ }^{1}$ draws attention to 'a unilateral process instituted by the HPCSA to embark on opening the diagnostic use of ionising radiation to all medical disciplines'. This is a reckless and alarming prospect.

As I write, the medical imaging industry throughout the USA, and the world at large, awaits the outcome of 2 days of hearings held on 30 and 31 March by the US Food and Drug Administration (FDA) regarding widespread concerns over rising medical radiation dose. These hearings were prompted by a rising tide of articles in the medical literature drawing attention to the danger posed by the increasing use of ionising radiation in medical diagnostic imaging, mainly a result of an explosive increase in the number of CT scans that are performed annually. The editorial quotes that more than 60 million CT scans are estimated to be performed annually in the USA. A further source ${ }^{2}$ (quoted in an article reviewing the hazards of ionising radiation) ${ }^{3}$ adds the perspective that in the 24-year period between 1981 and 2005, the number of CT examinations increased more than twentyfold, from 3 million in 1981 to 63 million in 2005.

In raising the alarm against what appears to be an unbelievably irresponsible move by the HPCSA (which appears bent on removing all control over diagnostic radiation in South Africa) at a time when the rest of the world is tightening control, the editorial surely speaks not only for the Radiological Society but for the entire radiological fraternity in South Africa. We, as the custodians of the appropriate use of ionising radiation for medical imaging, must make ready for battle.

\section{J Emby}

AngloGold Ashanti Health, Western Deep Levels Hospital, Carletonville demby@anglogoldashanti.com

1. Lotz J. Editorial: Radiation free-for-all is imminent. South African Journal of Radiology 2010; 14(1): 2

2. The delicate balance between radiation exposure and imaging efficiency. Leading article: InPractice; Quarterly Publication of the American Roentgen Ray Society. Summer 2007: 5-7.

3. Emby DJ. Radiation: Friend and foe. Occ Health Southern Africa 2008; 14(5): 9-13.

\section{The HPCSA and radiology}

To the Editor: Your editorial ${ }^{1}$ decrying the role of the HPCSA in allegedly encouraging a 'radiation free-for-all' nearly hit the mark (is it better to nearly hit or nearly miss?).
Allow me as a member of the maligned committee to make a few points.

The committee originated from a concern by the Radiation Control division of the Department of Health about unregulated radiological practices by practitioners, particularly in rural areas. Not only was radiation control often inadequate but the quality of the examinations was also often sub-standard. The issue was how to ensure the safety of the public while not depriving them of a service not otherwise available. From the outset, the Radiological Society was aware of this initiative and provided helpful documentation.

The committee noted that there were practitioners other than general practitioners (such as cardiologists etc.) who also used imaging in their practices. The general principle of the HPCSA in allowing practitioners to apply techniques for which they were adequately trained was considered to be appropriate also in these circumstances i.e. where specialists (such as cardiologists) demonstrably received adequate training, including the use of X-rays, they should be free to use this in subsequent practice.

However, general practitioners were not considered to have had sufficient training in radiological services, and the committee resolved that an appropriate training programme should be developed and completed by those who wished to provide a radiological service. The provision of such training for all users of imaging equipment is a well placed function of the RSSA.

There is general agreement that adequate radiation control is essential. But in my opinion there are more important issues that were not in the remit of the committee, namely the proliferation of many diagnostic and therapeutic interventions that are reliant on expensive equipment. Such equipment is often acquired because of its potential revenue generation, and that often results in self-referral - a sure way of driving up medical costs through unnecessary procedures.

\section{JP van Niekerk}

Health \& Medical Publishing Group

Rondebosch

jpvann@hmpg.co.za

1. Lotz J. Radiation free-for-all is imminent. South African Journal of Radiology 2010; 14: 2. 